\title{
Synthetic Lipid Nanoparticles Targeting Steroid Organs
}

\author{
Juliette Mérian ${ }^{1,2}$, Raphäl Boisgard ${ }^{1}$, Xavier Decleves ${ }^{3}$, Benoît Thezé ${ }^{1}$, Isabelle Texier ${ }^{2}$, and Bertrand Tavitian ${ }^{1,4}$ \\ ${ }^{1}$ Inserm U1023, I2BM/SHFJ, CEA, Orsay, France; ${ }^{2}$ CEA Leti, Minatec Campus, DTBS, Grenoble, France; ${ }^{3}$ Faculté de Pharmacie, \\ Université Paris Descartes, Paris, France; and ${ }^{4}$ Inserm UMR 970, PARCC; Université Paris Descartes, Sorbonne Paris Cité; \\ Assistance Publique-Hôpitaux de Paris, Hôpital Européen Georges Pompidou, Paris, France
}

\begin{abstract}
Lipidots are original nanoparticulate lipid delivery vectors for drugs and contrast agents made from materials generally regarded as safe. Here, we characterized the in vivo stability, biodistribution, and pharmacokinetics of lipidots. Methods: Lipidots $55 \mathrm{~nm}$ in diameter and coated with a phospholipid/poly(ethyleneglycol) surfactant shell were triply labeled with ${ }^{3} \mathrm{H}$-cholesteryl-hexadecyl-ether, cholesteryl- ${ }^{14} \mathrm{C}$-oleate, and the 1,1'-dioctadecyl-3,3,3',3'-tetramethylindotricarbocyanine infrared fluorescent dye and injected intravenously into immunocompetent Friend virus B-type mice. The pharmacokinetics and biodistribution of lipidots were analyzed quantitatively in serial samples of blood and tissue and with in vivo optical imaging and were refined by microscopic examination of selected target tissues. Results: The plasmatic half-life of lipidots was approximately $30 \mathrm{~min}$. Radioactive and fluorescent tracers displayed a similar nanoparticle-driven biodistribution, indicative of the lipidots' integrity during the first hours after injection. Lipidots distributed in the liver and, surprisingly, in the steroid-rich organs adrenals and ovaries, but not in the spleen. This tropism was confirmed at the microscopic level by histologic detection of 1,1'-dioctadecyl$3,3,3^{\prime}, 3^{\prime}$-tetramethylindotricarbocyanine. Nanoparticle loading with cholesterol derivatives increased accumulation in ovaries in a dosedependent manner. Conclusion: This previously unreported distribution pattern is specific to lipidots and attributed to their nanometric size and composition, conferring on them a lipoproteinlike behavior. The affinity of lipidots for steroid hormone-rich areas is of interest to address drugs and contrast agents to lipoprotein-receptor-overexpressing cancer cells found in hormone-dependent tumors.
\end{abstract}

Key Words: lipid nanoparticles; pharmacokinetics; biodistribution; in vivo imaging; lipoproteins

J Nucl Med 2013; 54:1996-2003

DOI: 10.2967/jnumed.113.121657

$\mathbf{T}$ he use of nanocarriers is becoming increasingly popular to improve the bioavailability of therapeutics and contrast agents. The low cytotoxicity and high loading capacity of synthetic lipidbased nanoparticles limit adverse side effects, enhance delivery to

Received Feb. 14, 2013; revision accepted Jun. 4, 2013.

For correspondence or reprints contact any of the following: Bertrand

Tavitian, Inserm U970, 56 rue Leblanc, 75015 Paris, France.

E-mail: bertrand.tavitian@inserm.fr

Isabelle Texier, CEA Leti, Minatec Campus, DTBS, 17 avenue des Martyrs,

38054 Grenoble Cedex 9, France.

E-mail: isabelle.texier-nogues@cea.fr

Juliette Mérian, LETI/DTBS, CEA Grenoble, 17 avenue des Martyrs, 38054

Grenoble Cedex 9, France.

E-mail: juliette.merian@gmail.com

Published online Sep. 26, 2013.

COPYRIGHT @ 2013 by the Society of Nuclear Medicine and Molecular Imaging, Inc. biologic targets, and reduce metabolism and distribution to undesired sites (1-3). Lipidots are newly described lipid nanoparticles based on oil-in-water nanoemulsion templates made of components generally regarded as safe $(4,5)$, forming colloidal dispersions of lipid droplets with finely tuned core/shell properties and stable for several years $(4,5)$. These particles display no cellular toxicity and can incorporate high amounts of organic fluorescent dyes (6). Systemic administration of fluorescent dye-loaded lipidots carrying the cyclic arginine-glycine-aspartate peptide, a ligand of $\alpha_{v} \beta_{3}$ integrins highly expressed in the tumor vasculature, produced in vivo images of subcutaneously grafted cancer cells in mice (7) originally interpreted as resulting from ligand-specific uptake. However, similar levels of tumoral uptake were observed after administration of lipidots carrying a control cyclic argininealanine-aspartate peptide that does not bind to $\alpha_{v} \beta_{3}$ integrins (7). This unexpected observation suggested that arginine-glycine-aspartate binding to tumoral integrins was not the main force driving the lipidots' uptake into tumors and raised concerns as to the actual uptake mechanism. One possibility may have been the degradation of lipidots in plasma, yielding separate components taken up independently in tumors. Alternatively, tumor uptake of lipidots could have been a consequence of passive retention through the enhanced permeability and retention effect (8). Both caveats may also have combined to drive the in vivo biodistribution of lipidots. Therefore, the prime objective of this study was to explore the stability, biodistribution, and pharmacokinetics of lipidots in vivo.

In contrast to the sequential metabolism of small molecules, the degradation of organic nanoparticles is a combination of their breakdown into separate components and of the metabolism of these components, gradually releasing moieties that are ill-defined in their composition, physical properties, and tissue distribution (9). Easily quantifiable analytic methods such as inductively coupled plasma mass spectroscopy are not applicable to organic nanoparticles. Hence, we turned to radiolabeling techniques based on the introduction of ${ }^{14} \mathrm{C},{ }^{3} \mathrm{H}$, or ${ }^{125} \mathrm{I}$ radionuclides in polymer backbones (10-12), liposomes (13-15), or lipid nanoparticles (16-18). We triply labeled lipidots with 2 radiotracers and a fluorescent dye with close physicochemical properties favoring their colocalization in the particle's core, that is, a slightly polar head (cyanine or cholesterol moiety) and long hydrophobic chain or chains. The 2 radiotracers, 1,2- ${ }^{3} \mathrm{H}(N)$-cholesteryl-hexadecyl ether $\left({ }^{3} \mathrm{H}-\mathrm{CHE}\right)$ and cholesteryl-1- ${ }^{14} \mathrm{C}$-oleate $\left({ }^{14} \mathrm{C}-\mathrm{CHO}\right)$, both previously used for liposome development $(14,15,19)$, have different metabolic profiles: the ether link between the tritiated cholesteryl moiety and the lipid chain prevents metabolization of ${ }^{3} \mathrm{H}-\mathrm{CHE}$, whereas ${ }^{14} \mathrm{C}-\mathrm{CHO}$ is hydrolyzed in cells but not significantly in plasma (13). The nearinfrared fluorescent dye 1,1'-dioctadecyl-3,3,3',3'-tetramethylindotricarbocyanine perchlorate (DiD), a cyanine bound by an amine 
link to 2 lipophilic C18 chains, is efficiently incorporated in lipidots with long-term stability (6).

We report the pharmacokinetics and whole-body biodistribution of triply labeled lipidots in mice. Results from organ counting and fluorescence detection were confirmed by live optical imaging and ex vivo histologic examination of target organs. Unexpectedly, lipidots showed specific uptake in steroid organs. Unexpectedly, lipidots showed specific uptake in steroid organs, which to our knowledge has never yet been reported for a lipid nanoparticle.

\section{MATERIALS AND METHODS}

\section{Chemicals}

Suppocire NB was kindly donated by Gattefosse. Myrj-s52 (poly [ethyleneglycol] [PEG] 40 stearate) and superrefined soybean oil were gifts from CRODA. Lipoid-s75 was purchased from Lipoid $\mathrm{GmbH}$; ${ }^{3} \mathrm{H}-\mathrm{CHE},{ }^{14} \mathrm{C}-\mathrm{CHO}$, Soluene-350, and Hionic-Fluor from Perkin Elmer; DiD from Invitrogen; immunohistochemical zinc fixative $\times 10$ from BD Pharmingen; paraformaldehyde from Labonord; and other products from Sigma-Aldrich.

\section{Nanoparticle Preparations}

Preparation of triply labeled lipidots was adapted from protocols detailed elsewhere (4-7). Briefly, an oily mixture composed of soybean oil $(23 \mathrm{mg})$, Suppocire NB (68 mg), and Lipoid-s75 (17 mg); $\mathrm{DiD}(1.6 \mu \mathrm{mol}$, ethanol); and the radiotracers $(12.9 \mathrm{MBq}$ [348 $\mu \mathrm{Ci}]$ of ${ }^{3} \mathrm{H}-\mathrm{CHE}$ and $3.3 \mathrm{MBq}[88 \mu \mathrm{Ci}]$ of ${ }^{14} \mathrm{C}-\mathrm{CHO}$, supplied in toluene: ethanol 3:1 v:v), was mixed with an aqueous phase composed of Myrj-s52 (stearate- $\mathrm{PEG}_{40}, 92 \mathrm{mg}$ ) and $500 \mathrm{mg}$ of glycerol in 1,800 $\mu \mathrm{L}$ of $10 \mathrm{mM}$ phosphate-buffered saline (PBS), $\mathrm{pH}$ 7.4. The radiotracers contributed $0.6 \%$ (w:w) and $\mathrm{DiD} 0.08 \%$ (w:w), respectively. Sonication cycles were performed at $15^{\circ} \mathrm{C}$ for $10 \mathrm{~min}$ to yield $55-\mathrm{nm}$ triply labeled lipidots, which were protected from light and dialyzed overnight in $\times 1$ PBS at room temperature. Samples were sterilized on $0.22-\mu \mathrm{m}$ filters and diluted to adjust the dose of radioactivity and fluorescence for characterization and in vivo injection. The preparation of enriched formulations was similar except that cholesterol $(\mathrm{CH}$, $0.6 \%$ or $2.0 \%(\mathrm{w}: \mathrm{w})$ ) or cholesteryl stearate (CHST, $0.6 \%$ or $2.0 \%$ (w: w)) was added to the oily premix.

\section{Nanoparticle Characterization}

The hydrodynamic diameter, polydispersity index, and $\zeta$ potential of the lipid nanoparticles were measured with a Zeta Sizer Nano instrument (NanoZS) in $\times 0.1$ PBS buffer. Optical properties of the lipidots were characterized using a Cary 300 Scan spectrophotometer (Varian) for ultraviolet/visible light absorption and an LS50B fluorimeter (Perkin-Elmer) for emission. Radiotracer encapsulation yields were calculated by measuring radioactivity in the sample and in the dialysis water bath before and after extensive dialysis. Coencapsulation of the 3 tracers was controlled by size-exclusion chromatography of a $10-\mu \mathrm{L}$ aliquot through a PD 10 column (Sephadex G25; particle size range, 85-260 $\mu \mathrm{m}$; GE Healthcare). Two hundred-microliter samples were collected, radioactivity was counted on a 2200CA TRiCarb liquid scintillation analyzer (Packard) after addition of $10 \mathrm{~mL}$ of Hionic-Fluor, and fluorescence of the cyanine dye DiD (maximum absorption and emission wavelengths, 645 and $665 \mathrm{~nm}$, respectively) was measured on a Fluobeam-700 (Fluoptics Grenoble) using a $100-\mathrm{ms}$ acquisition time. Fluobeam is an openfield imaging system combining near-infrared fluorescence excitation by a 690 -nm laser and white-light-emitting diodes (LEDs). Dedicated optics scatter the laser and LED light over a field $6 \mathrm{~cm}$ in diameter at a distance of $15 \mathrm{~cm}$. The power density of laser irradiation on tissue is $52 \mu \mathrm{W} / \mathrm{mm}^{2}$. The fluorescence signal is collected through a high-pass filter over $700 \mathrm{~nm}$.

\section{Animal Experimentation}

Animal studies were approved by the animal ethics committee of Institut d'Imagerie Biomédicale and conducted in accordance with Directive 2010/63/EU of the European Parliament on healthy Friend virus B-type (FVB) female mice (6 wk old; Janvier Labs) weighing 22-25 g. All injections were made through the tail vein by bolus injection in $100-\mu \mathrm{L}$ volumes using 29 -gauge syringes.

\section{Pharmacokinetics Study}

Three mice were injected with $1.2 \times 10^{13}$ nanoparticles in $100 \mu \mathrm{L}$ of PBS (46 mg/kg lipids, $49.2 \mathrm{kBq}[1.33 \mu \mathrm{Ci}]$ of ${ }^{3} \mathrm{H}-\mathrm{CHE}, 14.1 \mathrm{kBq}$ [0.38 $\mu \mathrm{Ci}]$ of ${ }^{14} \mathrm{C}-\mathrm{CHO}$, and $9.2 \mathrm{nmol}$ of $\left.\mathrm{DiD}\right) ; 3$ mice were injected with the free radiotracers $\left(49.2 \mathrm{kBq}[1.33 \mu \mathrm{Ci}]\right.$ of ${ }^{3} \mathrm{H}-\mathrm{CHE}$ and 14.1 $\mathrm{kBq}[0.38 \mu \mathrm{Ci}]$ of ${ }^{14} \mathrm{C}-\mathrm{CHO}$ in $100 \mu \mathrm{L}$ of PBS with $1.33 \%: 3.8 \% \mathrm{v}: \mathrm{v}$ toluene:ethanol); 3 mice were injected with free $\mathrm{DiD}(9.2 \mathrm{nmol}$ in 100 $\mu \mathrm{L}$ of PBS with $1.5 \%$ (w:w) polysorbate 80 ). For each sampling time point, $10-\mu \mathrm{L}$ blood samples were collected retroorbitally in anesthetized animals, placed into scintillation vials, dissolved with Soluene-350, bleached using hydrogen peroxide (30\%), mixed with Hionic-Fluor, and counted on a $\beta$ counter (TRiCarb; Packard). A diluted sample of the injected solution was used to quantify radioactivity measurements. Results are expressed in percentage injected dose $(\%$ ID) per gram or cubic centimeter of tissue. Pharmacokinetics parameters were calculated by bicompartmental analysis using WinNonlin, version 3.2 (Pharsight), and statistical analyses were performed with $\mathrm{R}$ software using a bilateral $t$ test (matched variables), with $\alpha$ equal to 0.05 .

\section{Biodistribution Study}

The composition of the injected solutions was the same as for the pharmacokinetics study. Mice ( $n=3$ per time point) were divided into 3 groups: group 1 received triply labeled nanoparticles $(n=30)$, group 2 the free radiotracers $(n=15)$, and group $3 \mathrm{DiD}$ in polysorbate $80(n=15)$. Three mice were used to quantify tissue autofluorescence. Fluorescence imaging was performed on a Fluobeam 700 (Fluoptics) on shaved animals (Nair cream; Church and Dwight Co., Inc.). Autofluorescence was measured before injection of lipidots. In vivo whole-body imaging of mice was performed under gas anesthesia (isoflurane:oxygen $2 \%$ ) at selected time points after injection. After the last imaging session, a $200-\mu \mathrm{L}$ blood sample was collected by cardiac puncture into heparinized tubes and centrifuged at 2,000 rpm for $10 \mathrm{~min}$ at room temperature. Tissue samples from liver, brain, spleen, heart, kidney, adrenals, uterus, ovary, fat, intestine, lung, salivary gland, muscle, and pancreas were excised and rinsed with saline. Organ fluorescence was measured, and a sample from each organ was weighed and placed into a $20-\mathrm{mL}$ scintillation counting vial. Two milliliters of tissue solubilizer (Soluene-350) were added to the vials and placed under agitation in an oven at $60^{\circ} \mathrm{C}$ until complete dissolution. Samples were allowed to cool, and $400 \mu \mathrm{L}$ of $30 \% \mathrm{H}_{2} \mathrm{O}_{2}$ were added. After complete bleaching, $10 \mathrm{~mL}$ of Hionic-Fluor were added, and the samples were mixed vigorously for $1 \mathrm{~min}$. Samples (10 $\mu \mathrm{L}$ ) of biologic fluids (plasma, blood cell pellet, and urine) were placed in scintillation vials and counted as described above. Fluorescence from organ and plasma samples was measured by Fluobeam 700 fluorescence imaging and analyzed using ImageJ software, after subtraction of autofluorescence measured for each organ in control mice. Cholesterol- or cholesteryl stearate-complemented lipidots were injected in healthy FVB female mice following the same protocol (100- $\mu \mathrm{L}$ injection, $9.2 \mathrm{nmol}$ of $\mathrm{DiD}, 1.2 \times 10^{13}$ particles). The mice were sacrificed $4 \mathrm{~h}$ after injection, and organs were dissected and imaged as described above.

\section{Histology}

Histologic analysis was performed on samples collected from mice injected with nonradioactive, DiD-only loaded nanoparticles. The 
mice were sacrificed $24 \mathrm{~h}$ after injection. The organs were removed and placed for $48 \mathrm{~h}$ in $20 \mathrm{~mL}$ of $\times 1$ immunohistochemical zinc fixative at $4^{\circ} \mathrm{C}$, followed by $24 \mathrm{~h}$ in $20 \mathrm{~mL}$ of paraformaldehyde $4 \%$-sucrose $20 \%$ at $4{ }^{\circ} \mathrm{C}$, and then were immersed in isopentane, frozen in liquid nitrogen, and stored at $-80^{\circ} \mathrm{C}$. Five-micrometer sections were cut on a CM $3050 \mathrm{~S}$ cryostat (Leica). Nuclei were stained with 4,6-diamino-2-phenylindole (DAPI), and fluorescence was observed after excitation by a metal halogenide lamp (120 W) on an Axio Observer Z1 microscope (Carl Zeiss SAS) with an Axiocam MRm monochrome cooled camera (ICX 285 detector [Sony] in the 350- to 1,000-nm range, with 12-bit encoding), through a Plan-Neofluar (Zeiss) $\times 20$ (numeric aperture, 0.50 ) objective with $\times 200$ magnification and a $0.35 \mu \mathrm{m} /$ pixel resolution. Three filter sets (Zeiss) were used: for DAPI, excitation G 365, beam splitter FT 395, and emission BP 445/50; for DiD, excitation BP 665/45, beam splitter FT 695, and emission BP 725/50; for autofluorescence, excitation BP 550/25 (HE), beam splitter FT 570 (HE), and emission BP 605/70 (HE). Fluorescence signals were captured and analyzed using Axiovision software (Zeiss).

\section{Tumor Uptake Assays}

The PyMT murine mammary carcinoma model (20) was used to demonstrate the affinity of lipidots for hormone-dependent tumor cells. Two million PyMT tumor cells were implanted in the fat pad (fourth mammary gland) of 10-wk-old FVB female mice. Tumors were allowed to grow for 15-20 d until they reached a diameter of $0.5-0.7 \mathrm{~cm}$. Mice were shaven with Nair cream, and autofluorescence was quantified with the Fluobeam 700 (exposure time, $100 \mathrm{~ms}$ ). DiDloaded lipidots ( $100 \mu \mathrm{L}, 9.2 \mathrm{nmol}$ of DiD, $1.2 \times 10^{13}$ particles) were injected as described above and images acquired with the Fluobeam 700 (100-ms exposure time). Analysis was performed with ImageJ software after subtraction of auto-fluorescence recorded for the same organ in noninjected mice.

\section{RESULTS}

\section{Nanoparticle Characterization}

Triply labeled lipidots containing the 3 tracers ${ }^{3} \mathrm{H}-\mathrm{CHE},{ }^{14} \mathrm{C}$ $\mathrm{CHO}$, and DiD were obtained as $55 \pm 2 \mathrm{~nm}($ mean $\pm \mathrm{SD}, n=3)$ droplets with a polydispersity of 0.19 , in a concentrated particle dispersion $\left(1.2 \times 10^{15}\right.$ particles $/ \mathrm{mL}$ after dialysis $)$ with long-term stability $\left(>120 \mathrm{wk}\right.$ at $\left.4^{\circ} \mathrm{C}\right)(4,5)$. Because of the neutral PEG coating of the particles, the $\zeta$ potential of the droplets was close to $-5 \mathrm{mV}$.

After extensive dialysis, tracer encapsulation efficiency was $99.0 \% \pm 0.6 \%$ for the 2 radiotracers and $95 \% \pm 5 \%$ for DiD, whereas $0.8 \% \pm 0.06 \%$ of ${ }^{3} \mathrm{H}-\mathrm{CHE}$ and $0.9 \% \pm 0.01 \%$ of ${ }^{14} \mathrm{C}-$ $\mathrm{CHO}$ were recovered in the dialysis bath. DiD could not be detected in the dialysis bath because of its low solubility in water. The excellent encapsulation efficiencies result from the high affinity of the lipophilic tracers for the $\mathrm{C} 18$ oily phase of the particle core. The size-exclusion chromatography profile showed that all 3 tracers coeluted with the lipidots, confirming their coencapsulation (Supplemental Fig. 1; supplemental materials are available at http://jnm.snmjournals.org).

\section{Blood Pharmacokinetics of Lipidots}

Blood pharmacokinetics after intravenous injection of triply labeled lipidots showed similar time-activity curves for ${ }^{3} \mathrm{H}-\mathrm{CHE}$ and ${ }^{14} \mathrm{C}-\mathrm{CHO}$ up to $8 \mathrm{~h}$ after injection (Fig. 1). In contrast, free ${ }^{3} \mathrm{H}-\mathrm{CHE}$ or ${ }^{14} \mathrm{C}-\mathrm{CHO}$ was immediately washed out from the blood compartment after injection. Time-activity curves of ${ }^{3} \mathrm{H}-\mathrm{CHE}$ and ${ }^{14} \mathrm{C}-\mathrm{CHO}$ loaded in lipidots were fitted on a bicompartmental model

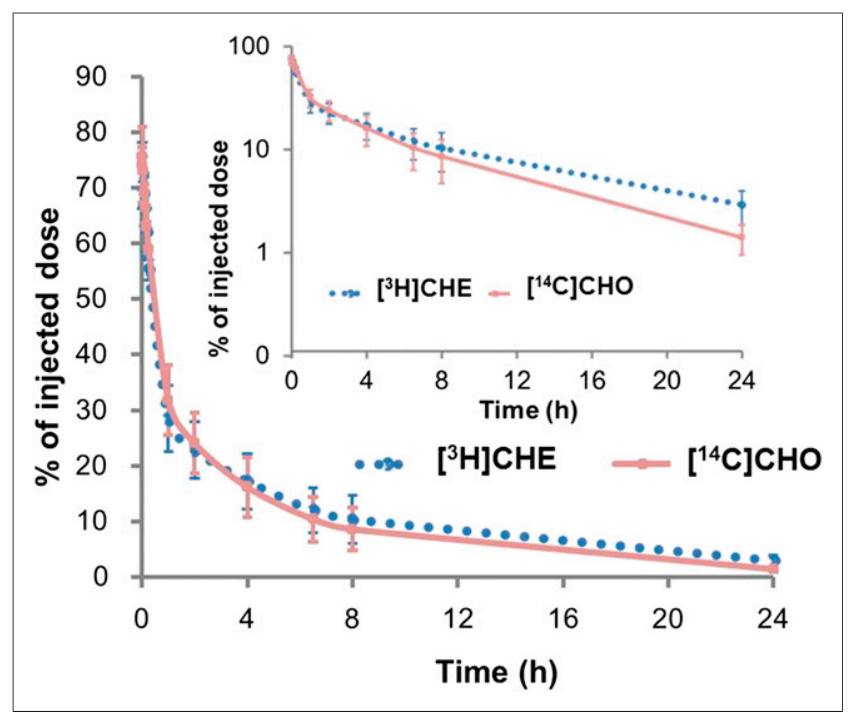

FIGURE 1. Blood kinetics of ${ }^{3} \mathrm{H}-\mathrm{CHE}$ and ${ }^{14} \mathrm{C}-\mathrm{CHO}$ after intravenous injection of triply labeled lipidots in mice (mean $\pm \mathrm{SD} ; n=3$ ). Inset: semilogarithmic plot of same data points.

(Table 1). The distribution phase half-life was similar ( $\sim 30 \mathrm{~min}$, $P=0.23$ ) for ${ }^{3} \mathrm{H}-\mathrm{CHE}$ and ${ }^{14} \mathrm{C}-\mathrm{CHO}$, whereas the elimination phases of the 2 tracers were statistically different after $8 \mathrm{~h}$ after injection $(P=0.012$, Fig. 1 inset). In all cases, plasma accounted for over $98 \%$ of whole-blood radioactivity.

\section{Organ Biodistribution of Lipidots}

Whole-body distributions of fluorescence and radioactivity were compared for the free tracers and the triply labeled lipidots (Fig. 2 and Supplemental Figs. 2-6). Concerning free radiotracers, the major organ of uptake was the lung, with maximum concentrations at $16 \mathrm{~h}$ after injection of $124 \pm 61$ and $261 \pm$ $160 \% \mathrm{ID} / \mathrm{g}$ for ${ }^{3} \mathrm{H}-\mathrm{CHE}$ and ${ }^{14} \mathrm{C}-\mathrm{CHO}$, respectively. In liver and spleen, radioactivity concentrations of ${ }^{14} \mathrm{C}-\mathrm{CHO}$ remained low: $12 \pm 2.8$ and $5.32 \pm 1.2 \% \mathrm{ID} / \mathrm{g}$, respectively, at $16 \mathrm{~h}$ after injection, whereas DiD fluorescence was found mainly in these 2 organs.

After injection of triply labeled lipidots, the 3 tracers were found mainly in the liver, ovaries, and adrenals, and only low levels were observed in the brain, heart, fat, intestine, muscle, pancreas, and salivary glands (Fig. 2B and Supplemental Figs. 3-6). No significant uptake was observed in the spleen, lung, kidney, or urine; high concentrations of the 3 tracers were recovered from the bile,

TABLE 1

Pharmacokinetic Parameters of ${ }^{3} \mathrm{H}-\mathrm{CHE}$ and ${ }^{14} \mathrm{C}-\mathrm{CHO}$ Derived from 2-Compartment Analysis After Intravenous Injection of Triply Labeled Lipidots in Mice

\begin{tabular}{lcc}
\hline \multicolumn{1}{c}{ Parameter } & ${ }^{14} \mathrm{C}$ & ${ }^{3} \mathrm{H}$ \\
\hline Half-life distribution $(\mathrm{h})$ & $0.50 \pm 0.13$ & $0.41 \pm 0.05$ \\
Half-life elimination $(\mathrm{h})$ & $5.83 \pm 0.4$ & $7.9 \pm 0.3$ \\
Mean residence time $(\mathrm{h})$ & $7.0 \pm 0.5$ & $10.2 \pm 0.8$ \\
Volume of distribution $(\mathrm{mL})$ & $4.3 \pm 0.8$ & $5.2 \pm 1$ \\
Systemic clearance $(\mathrm{mL} / \mathrm{h})$ & $0.62 \pm 0.1$ & $0.52 \pm 0.14$
\end{tabular}

Data are mean \pm SD. 


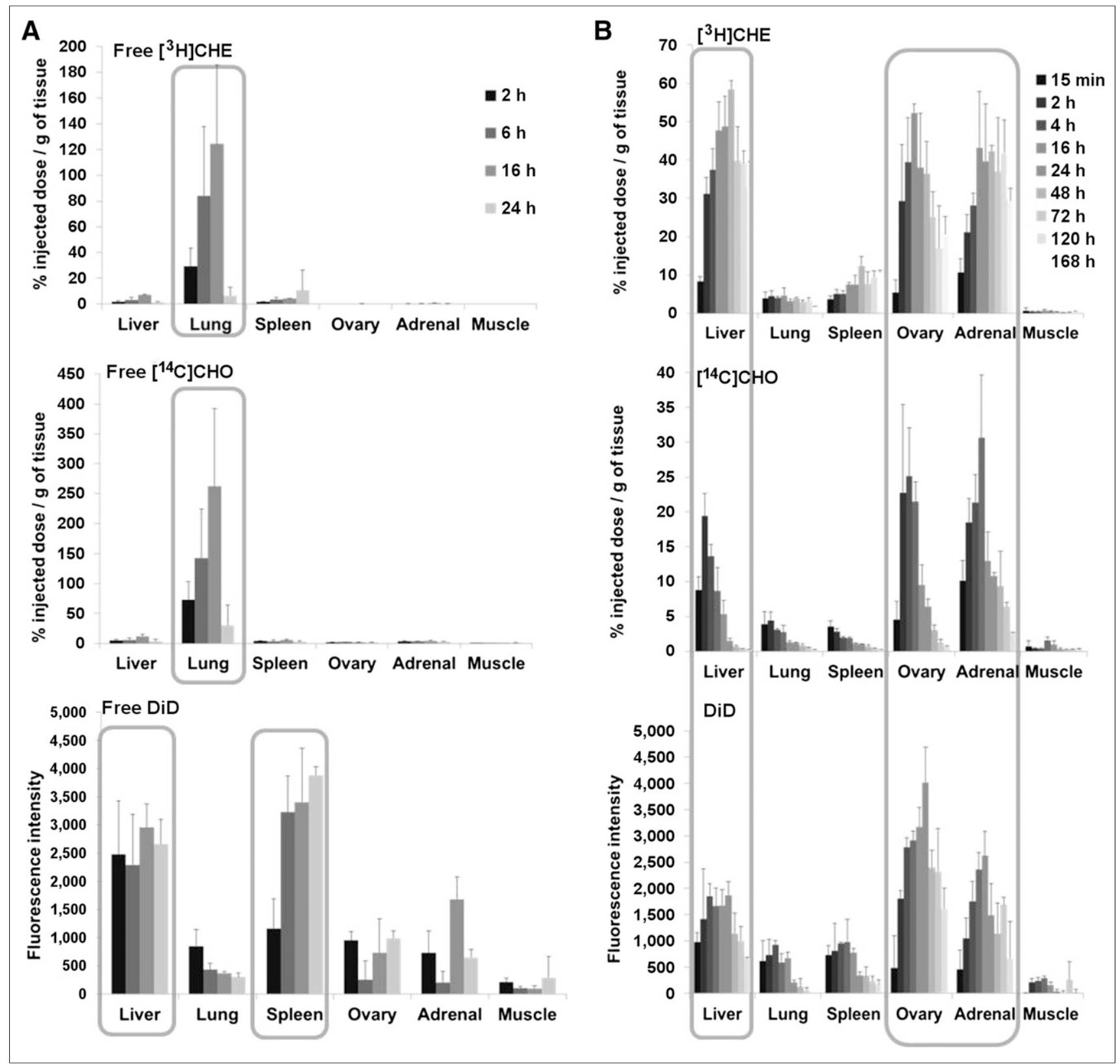

FIGURE 2. Quantitative tissue distribution after injection in mice of freely soluble tracers (A) or same tracers loaded in lipidots (B) (mean \pm SD; $n=$ 3 per time point).

albeit with a large interanimal variability. Altogether, uptake was major in gonadosteroid organs (i.e., liver, adrenals, ovaries), suggesting a specific tropism of lipidots for these organs.

The ratio of DiD fluorescence to ${ }^{3} \mathrm{H}$ radioactivity remained constant at all time points in plasma and organs (Supplemental Fig. 7). The ratio of ${ }^{14} \mathrm{C}$ to ${ }^{3} \mathrm{H}$ remained nearly constant in most organs up to a few hours after injection, except in the liver, for which the 2 signals diverted early, between $15 \mathrm{~min}$ and $2 \mathrm{~h}$ after injection. At $168 \mathrm{~h}$ after injection $(7 \mathrm{~d})$, high amounts of tritium radioactivity ( $>30 \% \mathrm{ID} / \mathrm{g}$ ) and DiD fluorescence were still present in the liver, whereas hepatic ${ }^{14} \mathrm{C}-\mathrm{CHO}$ radioactivity peaked at $19 \% \mathrm{ID} / \mathrm{g}$ at $2 \mathrm{~h}$ after injection and decreased steadily afterward $(0.2 \% \mathrm{ID} / \mathrm{g}$ at 168 h after injection) (Fig. 2 and Supplemental Figs. 4-7). Biliary concentrations of the tracers were heterogeneous because of vari- able hepatobiliary excretion rates among animals. Nevertheless, the fact that in the liver, ${ }^{14} \mathrm{C}$ counts corresponding to the metabolizable ester ${ }^{14} \mathrm{C}-\mathrm{CHO}$ decreased steadily while tritium counts and fluorescence, corresponding to nonmetabolizable ${ }^{3} \mathrm{H}-\mathrm{CHE}$ and $\mathrm{DiD}$, respectively, remained at high levels indicates that bile was the main elimination route for lipidots.

Tritium and fluorescence signals persisted also in the adrenals and ovaries: in the ovaries, uptake for ${ }^{3} \mathrm{H}$ maximized at $52 \pm 2.3$ $\% \mathrm{ID} / \mathrm{g}$ at $16 \mathrm{~h}$ after injection and still was $21 \pm 4.6 \% \mathrm{ID} / \mathrm{g}$ at $168 \mathrm{~h}$ after injection; in the adrenals, uptake for ${ }^{3} \mathrm{H}$ maximized at $43 \pm 14$ $\% \mathrm{ID} / \mathrm{g}$ at $16 \mathrm{~h}$ after injection and still was $29.3 \pm 3.3 \% \mathrm{ID} / \mathrm{g}$ at $168 \mathrm{~h}$ after injection, whereas uptake for DiD maximized $48 \mathrm{~h}$ after injection and decreased slowly until $168 \mathrm{~h}$ after injection. As in other organs, the time-activity curve of ${ }^{14} \mathrm{C}$ radioactivity was different: in 


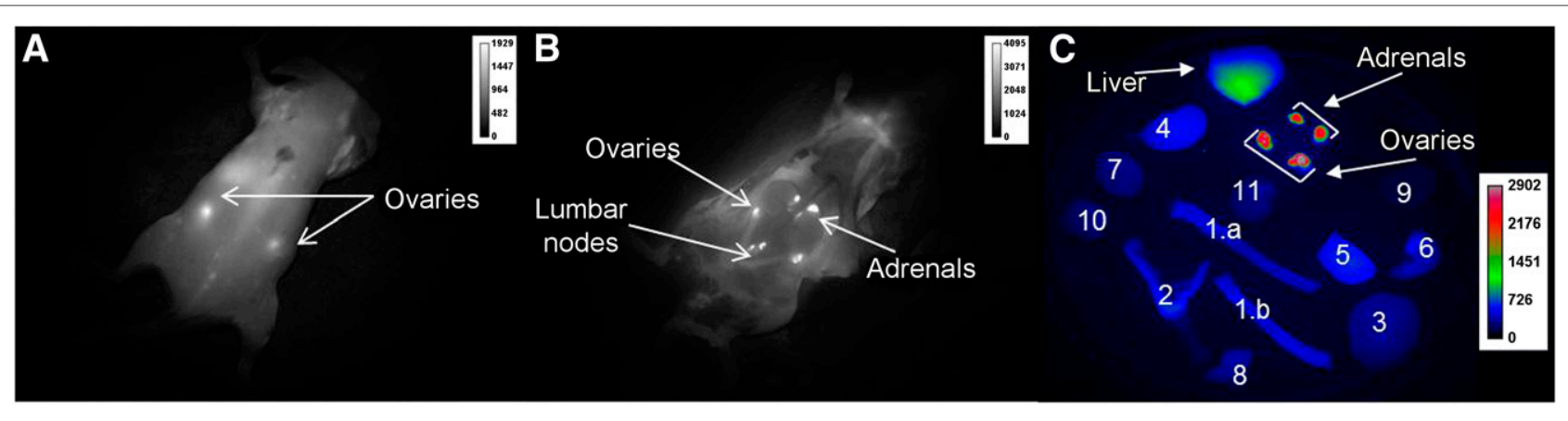

FIGURE 3. In vivo fluorescence imaging. (A) Representative image of FVB female mouse $24 \mathrm{~h}$ after intravenous injection of $1.2 \times 10^{13}$ DiD-loaded nanoparticles. (B) Representative image after laparotomy. (C) Ex vivo image of mouse organs at $24 \mathrm{~h}$ after injection. Acquisition times were set at 100 ms; contrast range was from 0 to 1,929 for $A, 0$ to 4,095 for $B$, and 0 to 2,902 for $\mathrm{C}$. $1=$ intestine; $1 \mathrm{a}=$ duodenum; $1 \mathrm{~b}=$ jejunum; $2=$ uterus; $3=$ brain; 4 = kidney; 5 = spleen; 6 = lung; 7 = salivary glands; 8 = pancreas; $9=$ muscle; $10=$ fat; $11=$ heart.

the ovaries, a peak of $25.1 \pm 6.9 \% \mathrm{ID} / \mathrm{g}$ was achieved at $4 \mathrm{~h}$ after injection whereas $0.74 \pm 0.08 \% \mathrm{ID} / \mathrm{g}$ was present at $168 \mathrm{~h}$ after injection; in the adrenals, the peak of $21.3 \pm 4.0 \% \mathrm{ID} / \mathrm{g}$ was achieved at $4 \mathrm{~h}$ after injection whereas $2.73 \pm 0.04 \% \mathrm{ID} / \mathrm{g}$ was present at $168 \mathrm{~h}$ after injection. Consequently, the ratio of ${ }^{14} \mathrm{C}$ to tritium counts decreased steadily in the main organs of uptake-that is, liver, adrenals, and ovaries-whereas the ratio of $\mathrm{DiD}$ fluorescence units to tritium counts remained constant in these organs a whole week after administration of lipidots (Supplemental Fig. 7).

DiD fluorescence levels in the ovaries were high enough to be observed directly through the skin of live mice $24 \mathrm{~h}$ after the injection of DiD-loaded lipidots (Fig. 3A). After laparotomy, DiD fluorescence created a clear contrast with adjacent tissue in the adrenals and ovaries (Fig. 3B and 3C). Fluorescence in lymph nodes was also observed, especially in the axillary and lumbar nodes. An uptake of lipidots in lymph nodes has been previously observed and is common to other inorganic and organic, especially lipid-based, nanoparticles (6).

\section{Histology}

Histologic analysis was performed ex vivo on tissue sections of the liver, spleen, kidneys, adrenals, and ovaries obtained after sacrifice of animals injected with lipidots. No autofluorescence signal was observed at the excitation or emission wavelength of $\mathrm{DiD}$ in the organs of control mice. After DiD-loaded lipidot injection, ovaries and adrenals were highly fluorescent, and homogeneous repartition of fluorescence was observed in the liver (Supplemental Figs. 8 and 9). In the ovaries, fluorescence was essentially observed in the corpus luteum bodies but not in other parts of the gland (Fig. 4A). In the adrenals, DiD fluorescence was prominent in the $\mathrm{X}$ zone located in the deepest layer of the cortex and absent from the medulla (Fig. 4B).

\section{Formulations Enriched in Cholesterol and Cholesteryl Stearate}

Lipidots enriched with cholesterol or cholesteryl stearate, in 2 different concentrations $(0.6 \%$ [w:w], corresponding to the total cholesterol present as ${ }^{14} \mathrm{C}-\mathrm{CHO}$ and ${ }^{3} \mathrm{H}-\mathrm{CHE}$, and $2.0 \%$ [w:w]) were prepared and administered to mice. Cholesterol is amphophilic and assumed to localize preferentially in the particle shell, whereas cholesteryl stearate is lipophilic and should preferentially localize in the oily core. The size and polydispersity of the lipidots were similar for cholesterol- and cholesteryl stearateenriched formulations and for nonenriched lipidots (Supplemental
Fig. 10). However, after $90 \mathrm{~d}$ at $4^{\circ} \mathrm{C}$, both cholesterol-enriched formulations depicted signs of destabilization (increase in size and polydispersity), whereas cholesteryl stearate-loaded lipidots remained stable during at least $130 \mathrm{~d}$.

Enrichment of lipidots with cholesteryl stearate induced a dosedependent increase in ovary uptake (Supplemental Fig. 10): uptake increased 1.6-fold for $0.6 \%$ (w:w) and 2.9-fold for $2.0 \%$ (w:w) cholesteryl stearate lipidots, with respect to labeled nonenriched lipidots; the ovary-to-muscle ratio was $11 \pm 3.0$ for $0.6 \%$ (w:w) cholesteryl stearate lipidots and $20 \pm 1.5$ for $2.0 \%$ (w:w) cholesteryl stearate lipidots. Addition of cholesterol alone had no effect on ovarian uptake: ovary-to-muscle ratios were $6.7 \pm 0.7,4.4 \pm$ 1.8 , and $6.8 \pm 1.4$ for nonenriched, $0.6 \%(\mathrm{w}: \mathrm{w})$, and $2.0 \%$ (w:w) cholesterol lipidots, respectively.

The tropism of lipidots toward organs involved in gonadosteroid synthesis prompted us to examine their uptake in a steroid-hormonedependent tumor. Figure 5 shows fluorescence images acquired after the injection of DiD-loaded lipidots in FVB mice that had received orthotopically implanted hormonodependent PyMT mammary cancer cells (20). High tumor-to-skin fluorescence ratios were reached in vivo $(3.5 \pm 0.6$ at $5 \mathrm{~h}$ after injection, $9.2 \pm 0.7$ at $24 \mathrm{~h}$ after injection) and were confirmed after organ resection (tumor-to-muscle fluorescence ratio of $9.3 \pm 0.5$ at $24 \mathrm{~h}$ after injection).

\section{DISCUSSION}

Lipidots are colloidal dispersions of lipid droplets with a finely tuned core diameter and internal viscosity, made of components

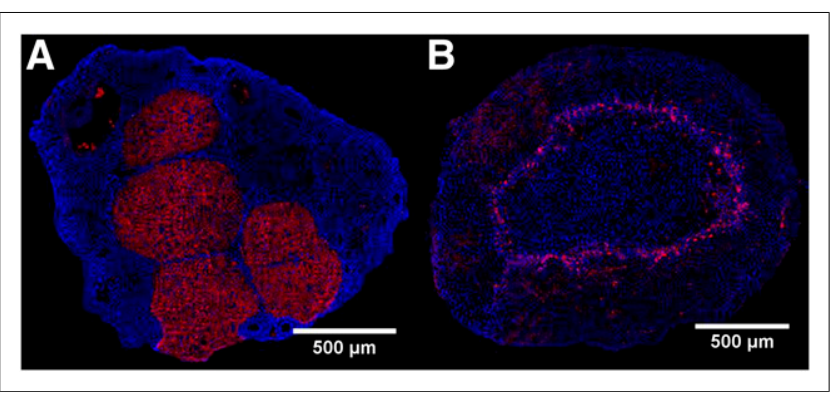

FIGURE 4. Localization of fluorescent lipidots in ovaries (A) and adrenals (B). DiD fluorescence is shown in red, cell nuclei stained with DAPI in blue. DiD accumulation can be seen in follicles and corpus luteum of ovary $(A)$ and in $X$ zone of adrenal $(B)$. 


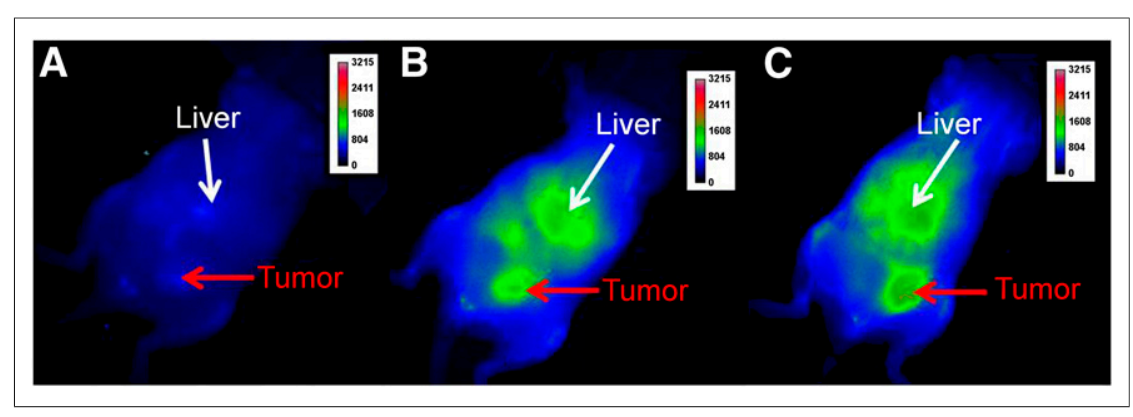

FIGURE 5. Uptake of DiD-loaded lipidots in PyMT mammary cancer cells. Fluorescence images were obtained before injection (A), $5 \mathrm{~h}$ after injection (B), and $24 \mathrm{~h}$ after injection (C).
In contrast to PEGylated solid lipid nanoparticles shown to accumulate in heart, muscle, kidneys, and brain $(1,3)$, lipidots homed preferentially to the liver, adrenals, and ovaries. Uptake of lipidots in the liver but not in the spleen is reminiscent of the uptake of lipoprotein complexes rather than that of most artificial nanoparticles. Small nanoparticles (e.g., quantum dots $<5.5 \mathrm{~nm}$ (24) or "soft" dendrimer nanoparticles < $15 \mathrm{~nm}(25))$ avoid phagocytosis and are cleared from the blood by the kidneys, but larger organic or inorganic nanoparticles accumulate in the spleen and liver generally regarded as safe, with a shelf-life in suspension of over 1 $\mathrm{y}$ and no cellular toxicity (4-6). The lipidots used in the present study were $55 \mathrm{~nm}$ in diameter, large enough to offer a sufficient volume for drug loading but small enough to limit uptake by macrophages of the reticuloendothelial system and favor extravasation and cell internalization (21). Lipidots have a high loading ratio for lipophilic molecules (6) and are coated with PEG to prevent surface protein adsorption and macrophage uptake $(1,2$, 21,22 ) and to favor long-term colloidal stability, neutrality of charge (4), and long plasma circulation times. Lipidots were loaded with 3 tracers presenting similar physicochemical properties, that is, a slightly polar cyanine or cholesterol head and long $\mathrm{C}_{16}$ or $\mathrm{C}_{18}$ hydrophobic chains. Lipidots loaded with cholesterol were less stable than those loaded with cholesteryl stearate, indicating that the tracers used in this study were preferentially located in the particle core or profoundly anchored in the particle shell by their $\mathrm{C}_{16} / \mathrm{C}_{18}$ tails.

An efficient container should safely transport its cargo to the destination and then release it. Triply labeled intravenously administered lipidots comply with these specifications as evidenced by the absence of leakage of the tracers in the blood compartment and the release of the tracers in specific organs. Lipidots circulated for over $24 \mathrm{~h}$ in blood and did not release any of the encapsulated tracers in the plasma, which would have been detected by homing of the tracers toward different organs (Fig. 2) (23). These results demonstrate the integrity of the lipidots, at least that of their core part containing the lipid tracers, during the initial phase of blood circulation and distribution to the organs.

To test for release of the lipidots' cargo in the organs of uptake, we used radiotracers with different metabolic stabilities: the ether link between the cholesteryl moiety and the lipid chain of ${ }^{3} \mathrm{H}-\mathrm{CHE}$ is nonexchangeable and nonhydrolyzed $(13,15)$; hence, this tracer accumulates in tissues without metabolization and is used to assess liposome and lipid nanoparticle biodistribution $(14,16,17)$. In contrast, ${ }^{14} \mathrm{C}-\mathrm{CHO}$ is stable in plasma but hydrolyzed within $2 \mathrm{~h}$ after cellular internalization (13). The DiD fluorophore loaded into lipidots has a long shelf life (6); little is known about its stability in vivo, but the fluorescence properties of DiD depend on its structural integrity and would be lost on degradation. The similar organ distribution of DiD, ${ }^{3} \mathrm{H}-\mathrm{CHE}$, and ${ }^{14} \mathrm{C}-\mathrm{CHO}$ at early time points after administration indicates that lipidots were taken up as intact nanoparticles into mouse tissues or at least that their core was intact. At later time points, decorrelation of the ${ }^{14} \mathrm{C}$ signal on the one hand from tritium and on the other hand from fluorescence signals reflects the release of the tracer cargo from lipidots into the organs. through phagocytosis by the mononuclear phagocyte system $(21,22)$. In contrast, chylomicrons and very low density lipoproteins (VLDL) are avidly and rapidly taken up in the liver; for example, $50 \%$ ID of VLDL labeled with small particles of iron oxide are present in liver $20 \mathrm{~min}$ after intravenous injection (26). Hepatocyte internalization of chylomicrons or VLDL in an apolipoprotein (especially apolipoprotein E)-dependent lipoprotein-receptor-mediated endocytosis (26) is already significant at $5 \mathrm{~min}$ after administration (26). A biodistribution avoiding the spleen suggests that, similarly to lipoprotein complexes, lipidots are taken up by liver hepatocytes rather than by Kupffer cells.

The observation of a high level of lipidot uptake in the adrenal glands and ovaries was unexpected. Fluorescence microscopy of histologic tissue sections further demonstrated a specific homing of lipidots to the ovarian follicles and to the deepest layer of the adrenal cortex, 2 steroid-rich regions where synthesis of steroid hormones takes place. In the ovaries, the theca cells of the follicles synthesize androgens that are aromatized by granulosa cells to produce estrogens, primarily estradiol; after ovulation, follicles turn into corpus luteum, which is loaded with lipids and secretes massive amounts of progesterone and other steroids. In the adrenal gland, the deepest layer of the cortex corresponds in humans to the pars reticularis, where male sexual hormones such as DHEA are synthesized. In mice and other rodents, the deepest supposed to be involved in progesterone and 11-deoxycorticosterone metabolism (28).

To the best of our knowledge, an accumulation of lipid nanoparticles in organs involved in the synthesis or storage of steroid hormones (the liver converts steroids into sexual hormones) was never reported previously. This peculiar tropism is a consequence of the lipid composition of lipidots, since it is increased by enrichment with cholesterol stearate in a dose-dependent manner. Few studies have addressed in vivo distribution of nanoparticles toward these organs, and the underlying mechanism is hypothetical. Accumulation in steroidogenic organs could be accounted for by both the nanometer size and the lipid nature of lipidots, turning them into "chylomicron/VLDL-like" particles after interaction with blood components. Indeed, lipoprotein receptors are overexpressed in adrenals and in the liver (29) and there are structural similarities between lipidots and natural chylomicrons or VLDL, including roughly similar sizes $(75-1,200,30-80$, and $55 \mathrm{~nm}$ for chylomicrons, VLDL, and lipidots, respectively) and a high shell content in phospholipids $(30,31)$. The surface of natural chylomicrons and VLDL is stabilized by amphophilic apolipoproteins, mainly apolipoprotein B-48 for chylomicrons and apolipoproteins layer of the mouse adrenal cortex is the so-called X zone (27), 
B-100 and E for VLDL, and apolipoproteins are the main plasma proteins that interact with PEGylated solid lipid nanoparticles $(32,33)$. Apolipoprotein AI efficiently binds and eventually enters phospholipid monolayers $(34,35)$. Coating with blood proteins is a promiscuous factor controlling the pharmacokinetics of nanoparticles $(21,36)$. It is reasonable to assume that lipidots could be coated by apolipoproteins in vivo, consequently be considered by the body as chylomicron- or VLDLlike particles, and undergo similar homing and biodistribution. The role of chylomicrons and VLDL in the transport of endogenous triglycerides and cholesteryl esters to peripheral tissues (31) could explain why the adrenals and ovaries, two organs that require high supplies of these compounds for hormone synthesis and in which lipoprotein receptors are overexpressed, accumulate lipidots. To confirm these hypotheses, future studies should explore whether cholesteryl ester transfer proteins (37) may transfer cholesteryl derivatives from lipidots to other lipoprotein complexes and whether lipidots show any affinity for specific cholesterol transporters such as the scavenger receptor class B, type I (38).

A possible chylomicron/VLDL mimicry of lipidots is also supported by the observation that cholesterol stearate-enriched lipidots, with a core composition close to that of chylomicrons and VLDL, exhibit higher uptake in the ovary than cholesterolenriched lipidots, which resemble cholesterol-rich lipoproteins (low-density and high-density lipoproteins) with different lipoprotein coats.

It has not escaped our attention that the specific affinity of lipidots for steroid hormone-rich areas or lipoprotein receptors is of interest for diagnostic and therapeutic applications. Overexpression of lipoprotein receptors by breast, ovarian, and prostate tumors (39) has been used for lipoprotein delivery of drugs and contrast agents for imaging and therapeutic purposes $(29,30)$. Two of the most frequent human carcinomas (breast and prostate) often express high levels of sex steroid receptors, and their proliferative capacity depends on sex steroid hormones $(39,40)$. In a proof-ofconcept experiment, we show that DiD-loaded lipidots accumulate in tumors implanted in mice from a mouse mammary carcinoma model, otherwise known to express estrogen and progesterone receptors and to depend on estradiol for tumor progression (20). This finding supports further investigations into the use of lipidots to deliver lipophilic drugs or contrast agents in hormone-dependent tumors or lesions, such as atheroma plaques.

\section{CONCLUSION}

We have documented the pharmacokinetics and biodistribution of lipidots, synthetic 55-nm-diameter lipid nanoemulsions with potential applications for diagnostics and drug delivery. After intravenous injection in healthy mice, lipidots are stable in blood and taken up preferentially in liver, adrenals, and ovaries, where they release their lipidic cargo. Lipidots depict an original biodistribution, not previously reported for other inorganic or organic nanoparticles, toward organs involved in steroid hormone synthesis and storage (adrenals and ovaries) and localize to precise sites in these organs, suggesting potential applications for imaging and drug delivery.

\section{DISCLOSURE}

The costs of publication of this article were defrayed in part by the payment of page charges. Therefore, and solely to indicate this fact, this article is hereby marked "advertisement" in accordance with 18 USC section 1734. This work was supported by the Commissariat à l'Energie Atomique et aux Energies Alternatives (CEA) and the Cancéropôle Lyon-Auvergne-Rhône-Alpes (PDC025 grant). No other potential conflict of interest relevant to this article was reported.

\section{ACKNOWLEDGMENT}

We thank Fabrice Navarro for comments on the manuscript.

\section{REFERENCES}

1. Blasi P, Giovagnoli S, Schoubben A, et al. Solid lipid nanoparticles for targeted brain drug delivery. Adv Drug Deliv Rev. 2007;59:454-477.

2. Joshi MD, Müller RH. Lipid nanoparticles for parenteral delivery of actives. Eur J Pharm Biopharm. 2009;71:161-172.

3. Mehnert W, Mäder K. Solid lipid nanoparticles: production, characterization and applications. Adv Drug Deliv Rev. 2001;47:165-196.

4. Delmas T, Couffin AC, Bayle PA, et al. Preparation and characterisation of highly stable lipid nanoparticles with amorphous core of tuneable viscosity. J Colloid Interface Sci. 2011;360:471-481.

5. Delmas T, Piraux H, Couffin AC, et al. How to prepare and stabilize very small nanoemulsions. Langmuir. 2011;27:1683-1692.

6. Gravier J, Navarro F, Delmas T, et al. Lipidots: a biocompatible alternative to quantum dots for in vivo fluorescence imaging. J Biomed Opt. 2011;16: 096013 .

7. Goutayer M, Dufort S, Josserand V, et al. Tumor targeting of functionalized lipid nanoparticles: assessment by in vivo fluorescence imaging. Eur J Pharm Biopharm. 2010;75:137-147.

8. Fang J, Nakamura H, Maeda H. The EPR effect: unique features of tumor blood vessels for drug delivery, factors involved, and limitations and augmentation of the effect. Adv Drug Deliv Rev. 2011;63:136-151.

9. Li M, Al-Jamal KT, Kostarelos K, et al. Physiologically based pharmacokinetic modeling of nanoparticles. ACS Nano. 2010;4:6303-6317.

10. Chen B, Jerger K, Fréchet JM, et al. The influence of polymer topology on pharmacokinetics: differences between cyclic and linear PEGylated poly(acrylic acid) comb polymers. J Control Release. 2009;140:203-209.

11. Sadekar S, Ray A, Janat-Amsbury M, et al. Comparative biodistribution of PAMAM dendrimers and HPMA copolymers in ovarian-tumor-bearing mice. Biomacromolecules. 2011;12:88-96.

12. Cao W, Ng KK, Corbin I, et al. Synthesis and evaluation of a stable bacteriochlorophyll-analog and its incorporation into high-density lipoprotein nanoparticles for tumor imaging. Bioconjug Chem. 2009;20:2023-2031.

13. Derksen JTP, Morselt HWM, Scherphof GL. Processing of different liposome markers after in vitro uptake of immunoglobulin-coated liposomes by rat liver macrophages. Biochim Biophys Acta. 1987;931:33-40.

14. Kawakami S, Munakata C, Fumoto S, et al. Novel galactosylated liposomes for hepatocyte-selective targeting of lipophilic drugs. J Pharm Sci. 2001;90: $105-113$.

15. Pool GL, French ME, Edwards RA, et al. Use of radiolabeled hexadecyl cholesteryl ether as a liposome marker. Lipids. 1982;17:448-452.

16. Hoarau D, Delmas P, David S, et al. Novel long-circulating lipid nanocapsules. Pharm Res. 2004;21:1783-1789.

17. Khalid MN, Simard P, Hoarau D, et al. Long circulating poly(ethylene glycol)decorated lipid nanocapsules deliver docetaxel to solid tumors. Pharm Res. 2006;23:752-758.

18. Rivkin I, Cohen K, Koffler J, et al. Paclitaxel-clusters coated with hyaluronan as selective tumor-targeted nanovectors. Biomaterials. 2010;31:7106-7114.

19. Mougin-Degraef M, Bourdeau C, Jestin E, et al. Doubly radiolabeled liposomes for pretargeted radioimmunotherapy. Int J Pharm. 2007;344:110-117.

20. Lin EY, Jones JG, Li P, et al. Progression to malignancy in the polyoma middle T oncoprotein mouse breast cancer model provides a reliable model for human diseases. Am J Pathol. 2003;163:2113-2126.

21. Moghimi SM, Hunter AC, Andersen TL. Factors controlling nanoparticle pharmacokinetics: an integrated analysis and perspective. Annu Rev Pharmacol Toxicol. 2012;52:481-503.

22. Almeida JPM, Chen AL, Foster AB, et al. In vivo biodistribution of nanoparticles. Nanomedicine. 2011;6:815-835.

23. Sasatsu M, Onishi H, Machida Y. In vitro and in vivo characterization of nanoparticles made of MeO-PEG amine/PLA block copolymer and PLA. Int J Pharm. 2006;317:167-174. 
24. Choi HS, Liu W, Misra W, et al. Renal clearance of quantum dots. Nat Biotechnol. 2007;25:1165-1170.

25. Longmire MR, Ogawa M, Choyke PL, et al. Biologically optimized nanosized molecules and particles: more than just size. Bioconjug Chem. 2011;22:9931000 .

26. Bruns OT, Ittrich H, Peldschus K, et al. Real-time magnetic resonance imaging and quantification of lipoprotein metabolism in vivo using nanocrystals. Nat Nanotechnol. 2009;4:193-201.

27. Keegan CE, Hammer G. Recent insights into organogenesis of the adrenal cortex. Trends Endocrinol Metab. 2002;13:200-208.

28. Hershkovitz L, Beuschlein F, Klammer S, et al. Adrenal 20alpha-hydroxysteroid dehydrogenase in the mouse catabolizes progesterone and 11-deoxycorticosterone and is restricted to the X-zone. Endocrinology. 2007;148:976-988.

29. Zheng G, Chen J, Li H, et al. Rerouting lipoprotein nanoparticles to selected alternate receptors for the targeted delivery of cancer diagnostic and therapeutic agents. Proc Natl Acad Sci USA. 2005;102: 17757-17762.

30. Ng KK, Lovell JF, Zheng G. Lipoprotein-inspired nanoparticles for cancer theranostics. Acc Chem Res. 2011;44:1105-1113.

31. Bricarello DA, Smolowitz JT, Zivkovic AM, et al. Reconstituted lipoprotein: a versatile class of biologically-inspired nanostructures. ACS Nano. 2011; $5: 42-57$.
32. Göppert TM, Müller RH. Protein adsorption patterns on poloxamer- and poloxamine-stabilized solid lipid nanoparticles (SLN). Eur J Pharm Biopharm. 2005;60:361-372.

33. Göppert TM, Müller RH. Adsorption kinetics of plasma proteins on solid lipid nanoparticles for drug targeting. Int J Pharm. 2005;302:172-186.

34. Lecompte M-F, Bras A-C, Dousset N, et al. Binding steps of apolipoprotein A-I with phospholipid monolayers: adsorption and penetration. Biochemistry. 1998;37:16165-16171.

35. Lund-Katz S, Nguyen D, Dhanasekaran P, et al. Surface plasmon resonance analysis of the mechanism of binding of apoA-I to high density lipoprotein particles. J Lipid Res. 2010;51:606-617.

36. Cullis PR, Chonn A, Semple SC. Interactions of liposomes and lipid-based carrier systems with blood proteins: relation to clearance behaviour in vivo. Adv Drug Deliv Rev. 1998;32:3-17.

37. Zhang L, Yan F, Zhang S, et al. Structural basis of transfer between lipoproteins by cholesteryl ester transfer protein. Nat Chem Biol. 2012;8:342-349.

38. Connelly MA, Williams DL. SR-BI and cholesterol uptake into steroidogenic cells. Trends Endocrinol Metab. 2003;14:467-472.

39. Folkerd EJ, Dowsett M. Influence of sex hormones on cancer progression. J Clin Oncol. 2010;28:4038-4044.

40. Stingl J. Estrogen and progesterone in normal mammary gland development and in cancer. Horm Cancer. 2011;2:85-90. 